\title{
GEOSPATIAL ANALYSIS OF IMPERVIOUS SURFACES AND THEIR EFFECT ON LAND SURFACE TEMPERATURE IN ABUJA, NIGERIA
}

\author{
E. A. Akomolafe ${ }^{1, *}$, O. A. Isioye ${ }^{2}$, J. U. Awulu ${ }^{3}$ \\ ${ }^{1,2,3}$ Department of Geomatics, Faculty of Environmental Design, Ahmadu Bello University, Zaria, Nigeria - \\ goldera2787@gmail.com, lekkyside4u@yahoo.com, awulujames580@gmail.com
}

\section{Commission IV}

KEY WORDS: Impervious surfaces, Land Surface Temperature (LST), Normalized Difference Impervious Surface Index (NDISI), Landsat ETM+/OLI/TIRS, Energy balance, Abuja city

\begin{abstract}
:
The rapid urban expansion in Abuja, Nigeria, has resulted in the replacement of land surface previously occupied by natural vegetation with various impermeable materials. This study examines the impact of the spatial distribution of impervious surfaces (IS) on land surface temperature (LST) in the study area using both graphical and quantitative approach. A Normalized Difference Impervious Surface Index (NDISI) was adopted to estimate IS and LST from Landsat ETM+ and OLI/TIRS satellite images (path: 189, row: 54) of Abuja for 4 distinct epochs of 2004, 2008, 2014 and 2018. In order to analyze the effect of IS on LST, the relationship between the normalized difference indices and LST, for each epoch, were determined using regression and correlation analyses. Results show the spatial patterns of impervious surfaces as distributed over Abuja, Nigeria and its impact on LST dynamics. It was observed that mean surface temperature increased by at least $2^{\circ} \mathrm{C}$ every 4 years. Furthermore, results of the correlation analysis between NDISI and LST reveal that there exist varying positive correlations between the two variables in with correlation coefficients; $\mathrm{R}=0.511,0.166,0.505$, 0.785 in 2004,2008, 2014 and 2018 respectively, suggesting that impervious surfaces areas accelerate LST rise and Urban Heat Island (UHI) formation. This study gives great insight on the concept of impervious surfaces and its spatial pattern in Abuja city, Nigeria. The study recommends the widespread use of highly reflective or natural surfaces for rooftops, pavements and roads and that afforestation should be encouraged to increase green areas.
\end{abstract}

\section{INTRODUCTION}

An important parameter employed in the assessment of the environment is the land surface temperature (LST), which is usually heavily influenced by surface structures. Rapid urbanization results in the replacement of natural land surfaces covered by vegetation, by various impervious features (Meiyappan and Jain, 2012). This urbanization in turn results in land cover types being converted from permeable surfaces to Impervious Surfaces (IS), arising as a consequence of anthropogenic activities. About $40 \%$ of the earth's surface is influenced by anthropogenic activities and impervious surfaces are gradually replacing the natural vegetation-dominated landscapes (Sterling and Ducharne, 2008). Qin, Jianhua (2014) noted that urban IS as a land cover type, have higher absorption of solar radiation, high thermal conductivity, and the ability to release heat stored during the day and night. Thus, IS have a warming effect on urban LST. This has a significant impact on the environment due to modification of heat energy balance. Impervious surface area has been used as a key environmental indicator over the years. The quality and availability of water quality can be reduced by IS areas, hence, leading to greater soil dryness and higher air temperatures. (Wu et al., 2014; Hua et al., 2020).

Several techniques have been created and utilized to extract IS area from remotely-sensed images with varying spatial resolutions and also to assess their dynamics. Three major algorithms have been used to extract IS from remote sensing images namely: spectral unmixing techniques, machine learning methods and spectral index (SI) methods. The machine learning methods include artificial neural networks (ANNs) (Voorde, Roeck \& Canters, 2009), support vector machines (SVMs) (Okujeni, Linden \& Hostert, 2015), decision tree classification
(DTC), classification and regression tree (CART) analysis (Xian and Crane, 2006), and regression modeling (Mohapatra, Wu, 2010). Meanwhile, amongst these techniques, spectral indices have been found, to measure the biophysical properties of the earth's surface. These include the impervious surface area index (Carlson and Arthur, 2000), the normalized difference impervious surface index (NDISI) (Xu, 2010), the biophysical composition index (BCI) (Deng, Wu, 2012; Meng et al., 2018), the modified NDISI (Liu et al., 2013), and the combinational built-up index (CBI) (Sun et al., 2016). This study made use of the NDISI to estimate the IS areas as it can efficiently enhance and extract impervious surfaces from satellite imagery, and the real proportion of IS can be represented.

The city of Abuja is currently experiencing rapid urbanization, hence, there is a rise in anthropogenic activities such as construction of roads, pavements, residential areas etc., all comprising of highly impervious surfaces. This increases the urban mean surface temperature over time (Adeyeri et al. 2015; Isioye, Ikwueze, Akomolafe, 2020). This concern is noticed in the formation of urban heat island, facilitated by IS. In Nigerian urban areas however, the effect of IS structure, its components, and its spatial distribution on LST has rarely been quantitatively studied. Therefore, analyzing the relationship between IS and LST is imperative in recognizing, controlling and mitigating the environmental impacts of urban heat islands in human-dominated landscapes, and planning the city of Abuja. This study examines the impact of the spatial distributions of IS on LST in the study area for a 14-year period from 2004 to 2018, using both graphical and quantitative approach; with a view to investigate the impact of IS on the urban heat environment. 


\section{STUDY AREA}

The study area is the Federal Capital Territory (FCT) of Nigeria, popularly known as Abuja city. It is located in central Nigeria between latitudes $8^{\circ} 25^{\prime} \mathrm{N}$ and $9^{\circ} 25^{\prime} \mathrm{N}$ and Longitudes $6^{\circ} 45^{\prime} \mathrm{E}$ and $7^{\circ} 45^{\prime} \mathrm{E}$, covering a land area of about $8,000 \mathrm{~km}^{2}$. As at April 2020 , the population of Abuja is estimated to be 2,996,670 people, based on worldometer elaboration of the latest United Nations data (Humanitarian Data Exchange, 2020). The city has a tropical wet and dry climate with an annual mean temperature ranging between $25.8^{\circ} \mathrm{C}$ and $30.2^{\circ} \mathrm{C}$. The annual rainfall is about 1,631.7mm between April and October yearly (Balogun, 2001). A map of the study area is shown in the Figure 1.

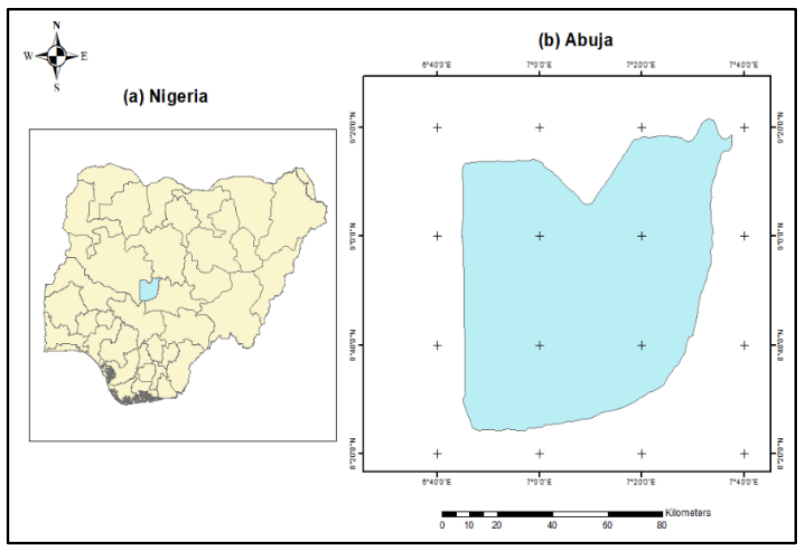

Figure 1 . The location of the study area

The elevation of Abuja, located at about $840 \mathrm{~m}$ above mean sea level, coupled with its undulating terrain, act as a regulating influence on the city's weather. Over time, Abuja has experienced a massive migration of people from the rural to the urban centres, which consequently has led to the creation of satellite towns to which the city is expanding. As a result, more vegetative coverings are being transformed into urban structures, thus, leading to a change in the micro-climate and UHI development.

\section{METHODS}

\subsection{Data Acquisition and Correction}

The data utilized in this study are remotely sensed satellite images. These include cloud free Landsat ETM+ and Landsat OLI/TIRS images of the study area for the years 2004, 2008, 2014 and 2018. These were obtained from the United States Geological Survey (USGS) website. The data are shown summarily in Table 1.

\begin{tabular}{|ccccc|}
\hline $\begin{array}{c}\text { Satellite/ } \\
\text { Sensor }\end{array}$ & Path/Row & $\begin{array}{c}\text { Acquisition } \\
\text { date }\end{array}$ & $\begin{array}{c}\text { Spatial } \\
\text { resolution }\end{array}$ & $\begin{array}{c}\text { Cloud } \\
\text { cover }\end{array}$ \\
\hline Landsat & $189 / 54$ & $18 / 01 / 2004$ & $30 \mathrm{~m}$ & $0 \%$ \\
ETM+ & & $14 / 02 / 2008$ & & \\
\hline Landsat & $189 / 54$ & $06 / 02 / 2014$ & $30 \mathrm{~m}$ & $0 \%$ \\
OLI/TIRS & & $01 / 02 / 2018$ & & \\
\hline
\end{tabular}

Table 1. Characteristics of satellite data used

The images were subjected to geometric and radiometric corrections to correct for sensor and platform-specific distortions due to variations in scene illumination and viewing geometry, atmospheric conditions, and sensor noise and response (Lillesand, Kiefer, 2004). With the corrections, the image pixels were converted from digital number (DN) to at-satellite reflectance. Furthermore, Landsat ETM+ Images defected with the scan line error were also corrected using the Landsat gap fill extension available in the ENVI 5.3 software.

\subsection{Retrieval of the Land Surface Temperature (LST)}

The thermal infrared bands of the Landsat ETM+ and OLI/TIRS images were used to estimate the LST in the study area as follows. First, the thermal bands were converted to spectral radiance and subsequently to at satellite brightness temperature as follows:

$$
L_{\lambda}=M_{L} \times Q C a l+A_{L},
$$

where $\quad \mathrm{L}_{\lambda}=$ at sensor spectral radiance in $\mathrm{Watt} /\left(\mathrm{m}^{2} \mathrm{sr} \mu \mathrm{m}\right)$

$\mathrm{M}_{\mathrm{L}}=$ the band-specific multiplicative rescaling factor as seen in the accompanying metadata file $\mathrm{QCal}=$ the standard product pixel value $(\mathrm{DN})$ $\mathrm{A}_{\mathrm{L}}=$ the band-specific additive rescaling factor from the metadata

The spectral radiance converted from pixel DN values above was then used to compute Top of Atmosphere (TOA) brightness temperature $\left(\mathrm{T}_{\mathbf{B}}\right)$ as follows.

$$
T_{B}=\frac{K_{2}}{\ln \left(\frac{K_{1}}{L_{\lambda}}+1\right)}
$$

Where $T_{B}=$ the effective at-satellite temperature

$\mathrm{K} 1$ and $\mathrm{K} 2$ are constants, seen in the accompanying metadata of Landsat images.

$\mathrm{T}_{\mathrm{B}}$ refers to a black body that is very distinct from the features of actual objects. Therefore, to compute LST, a correction for spectral emissivity $(\varepsilon)$ as to be applied to $\mathrm{T}_{\mathrm{B}}$. The emissivitycorrected LST (in Celsius) was computed as follows.

$$
\operatorname{LST}\left({ }^{\circ} C\right)=\frac{T_{B}}{\left[1+\left(\lambda \times \frac{T_{B}}{\rho}\right) \ln (\varepsilon)\right]}-273.15
$$

where $\lambda=$ the emitted radiance's wavelength

$\rho=\mathrm{h} \times(\mathrm{c} / \mathrm{s})=1.4388 \times 10^{-2} \mathrm{~m} \mathrm{~K}=14388 \mu \mathrm{m} \mathrm{K}$

$\mathrm{h}=$ Plank's constant $\left(6.626 \times 10^{-34} \mathrm{Js}\right)$

$\mathrm{s}=$ Boltzmann constant $\left(1.38 \times 10^{-23} \mathrm{~J} / \mathrm{K}\right)$

$\mathrm{c}=$ velocity of light $=2.998 \times 10^{8} \mathrm{~m} / \mathrm{s}$.

$\varepsilon=$ the surface emissivity

In this study, the NDVI threshold method was used to obtain land surface emissivity (Sobrino et al., 2004; Lia et al. 2013). For obtaining the results in Celsius, the radiant temperature is revised by adding the absolute zero (approx. $-273.15^{\circ} \mathrm{C}$ ).

\subsection{Derivation of Normalized Difference Vegetation Index (NDVI)}

The Normalized Difference Vegetation Index (NDVI) is calculated from the visible red and near infrared bands. The rationale of the index is that healthy vegetation has a high reflectance in the near infrared (NIR) and a low reflectance in the red, thereby enhancing the interpretation of vegetation cover while suppressing subtle noise from other land cover types. The formula used to derive NDVI is shown in equation (4).

$$
N D V I=\frac{N I R-R E D}{N I R+R E D}
$$


where

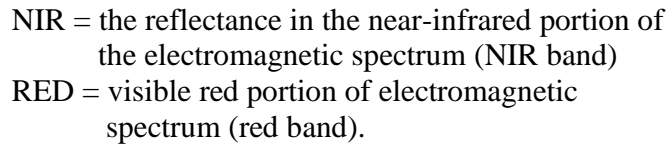

In this study, the NDVI water calculated for two fundamental reasons, i.e., understanding the city's vegetation pattern and extracting emissivity values.

\subsection{Retrieval of Impervious Surfaces (IS)}

The index-based technique was adopted in this study to map out the IS of Abuja. The thermal infrared (TIR), near-infrared (NIR), mid-infrared (MIR) and the visible (VIS) bands of the Landsat images were used to estimate the NDISI; depicting IS for each epoch, with values ranging from -1 to +1 . The NDISI is given by the following expression $(\mathrm{Xu}, 2010)$.

$$
N D I S I=\frac{T I R-\left[\left(V I S_{1}-N I R-M I R_{1}\right) / 3\right]}{T I R+\left[\left(V I S_{1}-N I R-M I R_{1}\right) / 3\right]}
$$

where $\quad$ NIR $=$ near-infrared band and

$\mathrm{MIR}_{1}=$ mid-infrared band (also referred to as the short-wave infrared)

$\mathrm{VIS}_{1}=$ any of the visible bands such as bands 1,2 or 3 of ETM+

The sum is divided by 3 so as to avoid a too minute value of the index. IS are characterized by high thermal emission, so the index takes advantage of this as well as its reduced reflection in MIR,
NIR and VIR bands respectively than in soil, vegetation and water $(\mathrm{Xu}, 2013)$. The NDISI can therefore isolate impervious features from non-impervious ones such as soil, water, and vegetation (Liu et al., 2010; $\mathrm{Xu}, 2010$ ).

\subsection{Statistical Analyses}

In this study, regression and correlation analyses were used to examine and analyze the impact of IS on urban surface temperature in Abuja city, so as to check the relationship between LST and the variables that the IS features comprise. This was achieved by examining its quantitative relationship with LST and vegetation represented by the NDVI. 150 sample points within the study area were selected for the statistical analysis. The points were distributed across conspicuous impervious surface features such as built-up area, pavements, bare surfaces, vegetation and water. The values of IS, LST and NDVI were extracted for each sample point for each epoch under study i.e. 2004, 2008, 2014 and 2018.

\section{RESULTS}

\subsection{Spatial Patterns of the LST}

The remote sensing technique of surface temperature estimation does not only give a quantitative measure of the scale of surface temperature of an entire expanse, but also provides the extent of the surface heat island impacts. The spatial distribution of the derived LST for the four study periods between 2004 and 2018 for Abuja city is shown in Figure 2.
2004

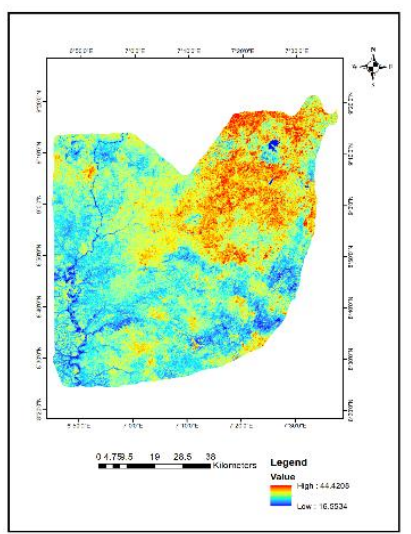

2008

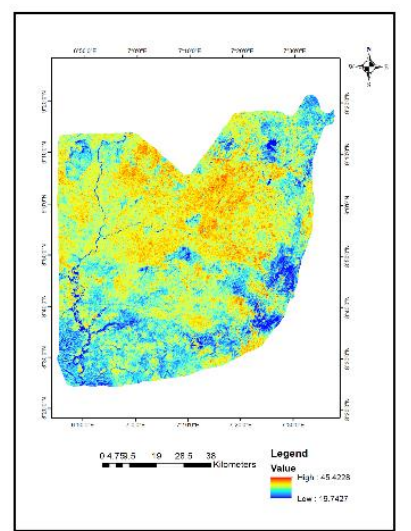

2014

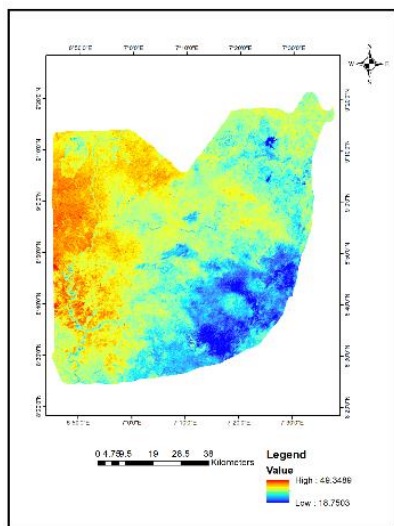

2018

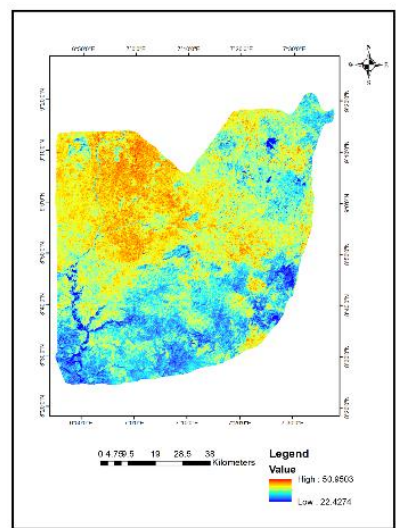

Figure 2. Spatial distribution of the LST in the year 2004, 2008, 2014 and 2018.

The LST within the city center obviously shows higher day-time surface temperature in the northern region than the southern region of the city, presenting pronounced surface urban heat island effect. Figure 3 depicts a graphical summary of the temperature variation revealing its maximum and minimum temperature for all years respectively. 


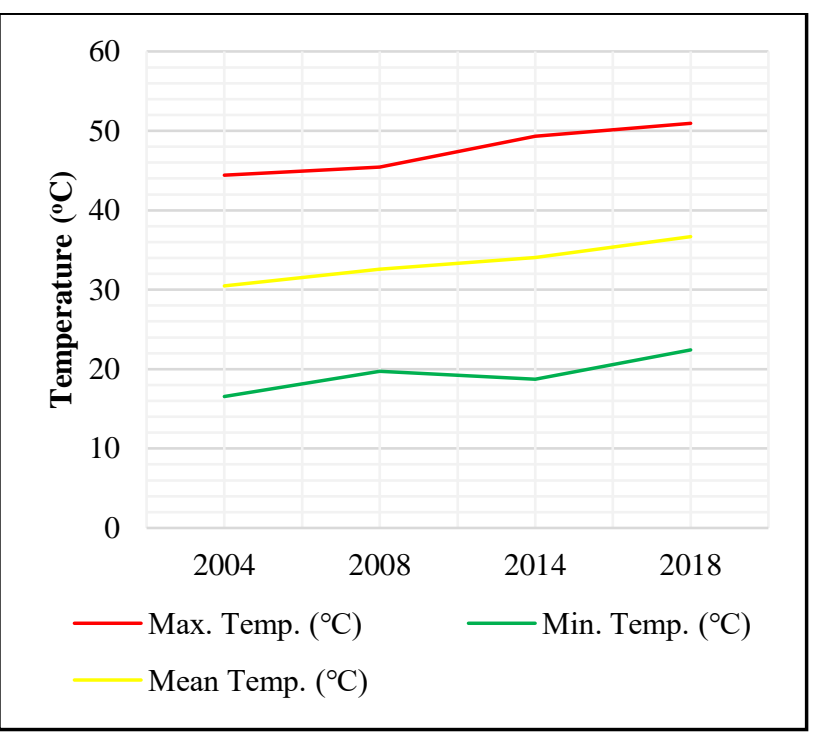

Figure 3. Summary of the LST trend between 2004 and 2018

The minimum to maximum ranges of the annual mean surface temperature in Abuja are $27.87^{\circ} \mathrm{C}, 25.56^{\circ} \mathrm{C}, 30.59^{\circ} \mathrm{C}, 28.53^{\circ} \mathrm{C}$ for 2004, 2008, 2014 and 2018 respectively (Figure 3). Results also show a gradual increase in mean surface temperature by at
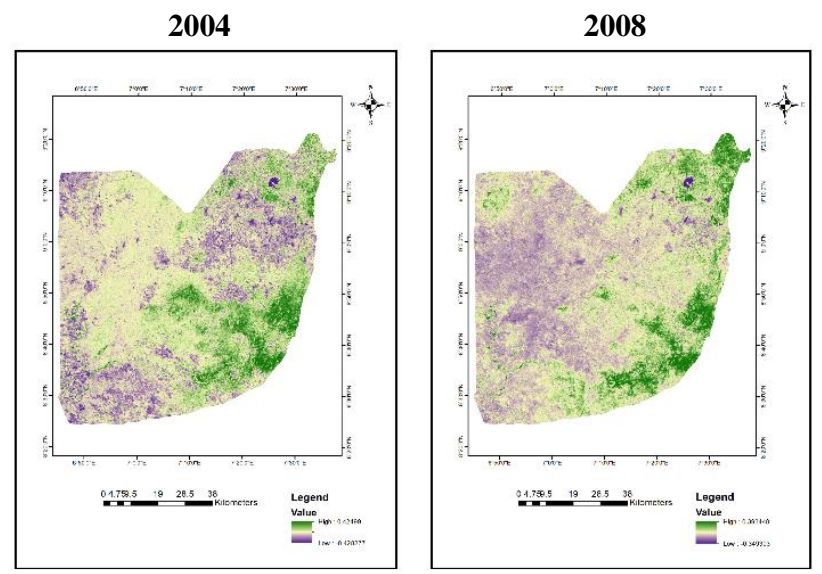

Figure 4. Spatial distribution of the

NDVI maps generated for the study area show that areas with highest NDVI values are sparse vegetation having values between 0.2 to 0.5 . The high NDVI values indicate abundance of vegetative cover as compared to areas with low NDVI values. Areas of high vegetation are mostly cultivated lands, grasslands and other undeveloped natural surfaces while areas with the least vegetation are the built-up urban areas, bare soil, water and rocks.

\subsection{Spatial patterns of Impervious Surfaces (IS)}

IS not only specifies the degree of urbanization, as a vital urban land cover feature, but it is also a significant influence to the least $2^{\circ} \mathrm{C}$ over the years within the study period, with a total average increase of $6^{\circ} \mathrm{C}$ between 2004 and 2018. This is evident in the rising slope of the mean temperature plot in Figure 3. Highest temperatures were observed in the regions where rapid urbanization is taking place, giving rise to more anthropogenic activities, as compared to the surrounding semi-urban areas mostly in the south of Abuja.

Adeyeri et al. (2015) and Isioye et al. (2020) also reported a consistent high UHI intensity in the northern part of Abuja city, compared to the downtown area. From the results obtained, it is observed that, a large portion of Abuja city experiences maximum LST of over $40^{\circ} \mathrm{C}$ in the study period. The high temperatures are detected in large commercial and residential areas due to influx of people and the possible air heating impacts of gases emitted from vehicles, building cooling systems and reflection or absorbance of roofing sheets.

\subsection{Spatial Patterns of Vegetation}

NDVI measures the density of the vegetative cover an area and tends to reduce with increase in the alteration of natural surfaces and replacing them with impervious surfaces (Adebayo et al., 2017). The spatial patterns of vegetation within the study area was investigated using the NDVI. Figure 4 shows the NDVI in Abuja city between 2004 and 2018.
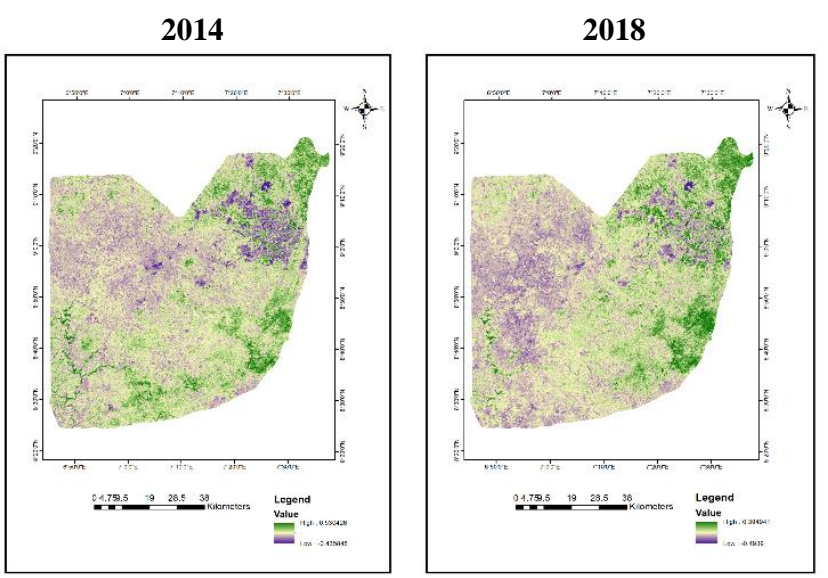

DVI in 2004, 2008, 2014 and 2018.

impacts of urbanization in the environment (Arnold and Gibbons, 1996). Results show the spatial patterns of IS as distributed over Abuja, Nigeria, incorporating urban IS such as rooftops, roads, parking lots and natural impervious surface such as wetlands, and waterbodies. The NDISI values for 2004 range between -0.75 and $0.32,-0.68$ and 0.15 for $2008,-0.85$ and 0.28 for 2014 and values between -0.77 and 0.18 for 2018 , representing maximum and minimum values of the index for the four epochs respectively. The NDISI maps for each epoch are shown in Figure 5. 
2004

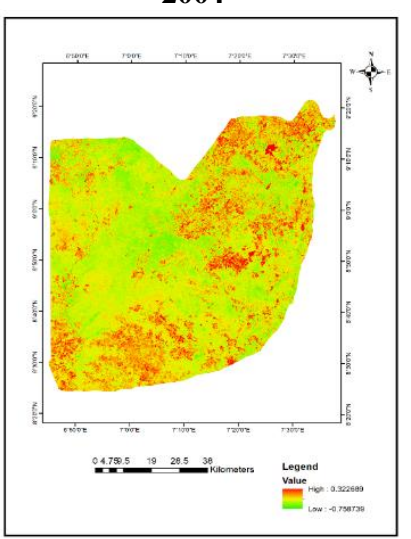

2008

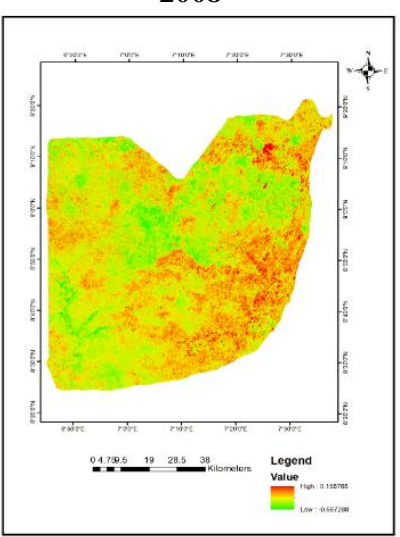

2014

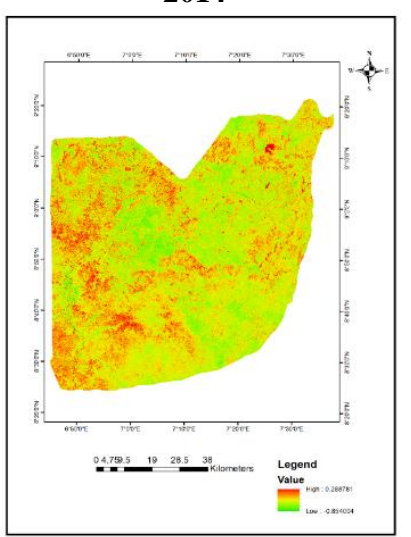

2018

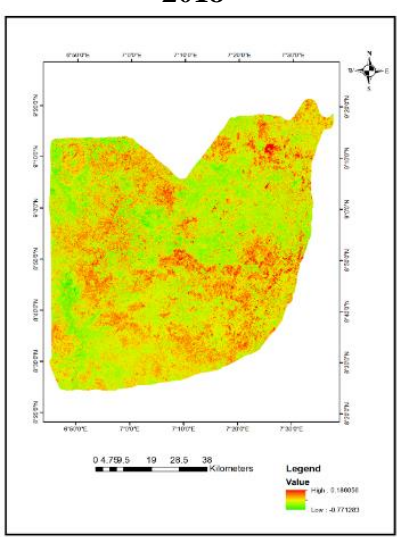

Figure 5. Spatial distribution of the NDVI in 2004, 2008, 2014 and 2018.

From the results obtained from the NDISI, it was observed that Abuja city underwent widespread urbanization, which in turn led to the creation of impervious surfaces, such as rooftops, roads, parking lots, sidewalks and driveways.

\subsection{Quantitative Relationships between LST and Thematic Indices}

Weng (2001) indicated that the best way to understand the impact of land cover changes on LST is to investigate the links between the thermal signatures and land cover types. The effects of IS and vegetation on LST variation was examined in this study trough

2004

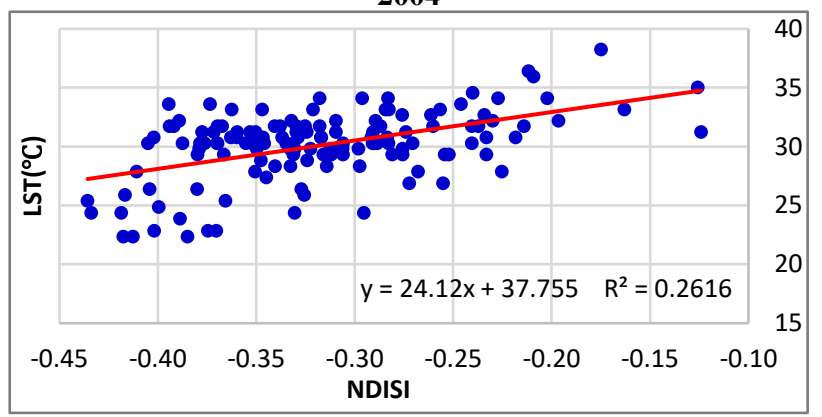

2014

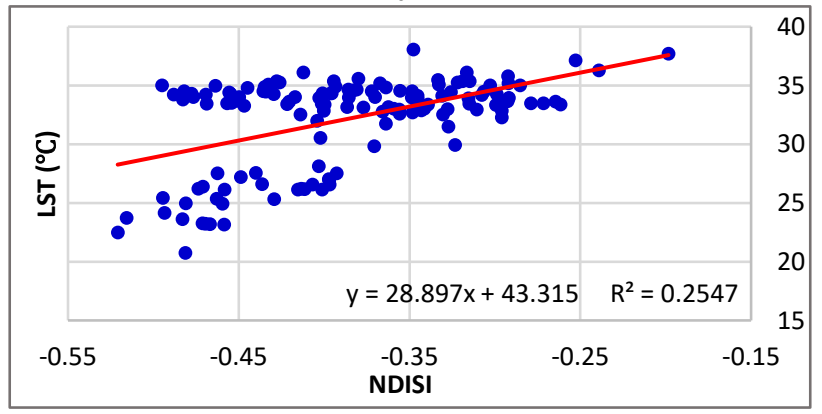

Figure 6. Correlation analysis between LST and NDISI in 2004, 2008, 2014 and 2018.

The results of the regression and correlation analyses to examine the impact of IS on LST in Abuja indicate positive correlations between impervious surface and LST for each epoch, with correlation coefficient values of $\mathrm{R}=0.511,0.166,0.505,0.785$ for the years 2004, 2008, 2014 and 2018 respectively, all at 95\% confidence interval. This demonstrates that the development of regression analysis, with LST as the dependent variable and the indices as the independent variables. While NDISI was used to quantify IS, NDVI was used to quantify vegetation cover in Abuja city.

4.4.1 Relationships of LST and Impervious Surface: In order to understand the thermal impact of urban expansion on the environment, it is important that planners have a good understanding of the relationship that exist between IS and surface temperature (Xu et al., 2013). Values of LST and IS extracted to 150 sample points, identical to all epochs in this study were used for the regression analysis. Results obtained are shown in Figure 6.

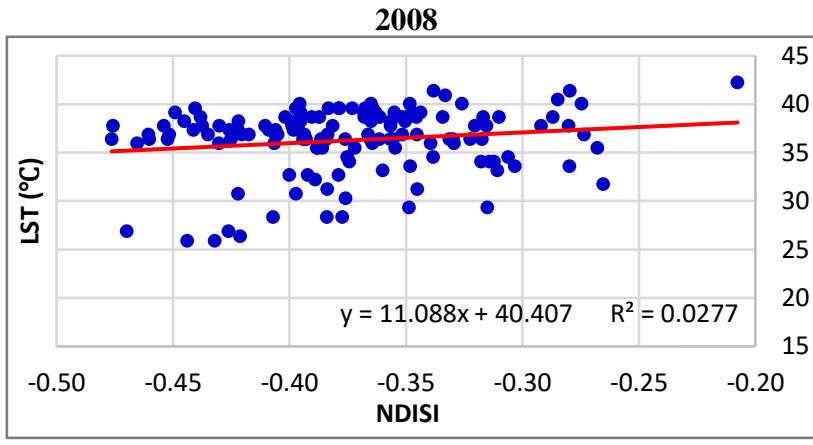

2018

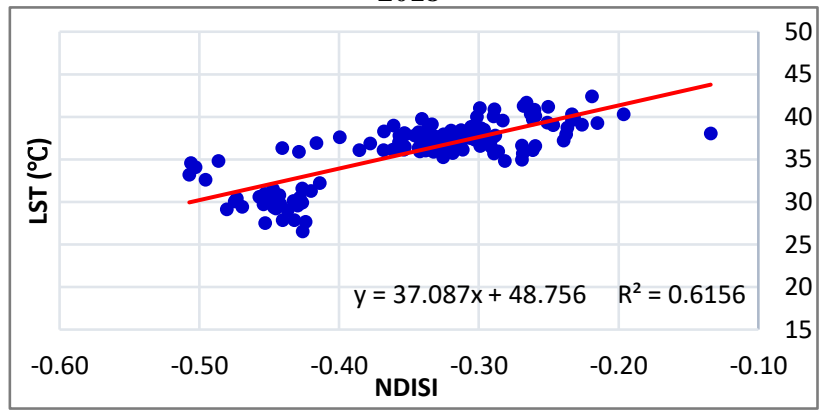

impervious surface contributes to temperature rise in Abuja city and it further suggests that the surface temperature rise in highly dense impervious surface areas is faster than in lowly dense impervious surface areas. This can be seen in the values of NDISI corresponding to the LST at each sample point. 
4.4.2 Relationships of LST and NDVI: The relationship between the LST and NDVI was analyzed, to test the correlation between these variables. This was achieved by running a regression analysis. Results are presented in Figure 7.

2004

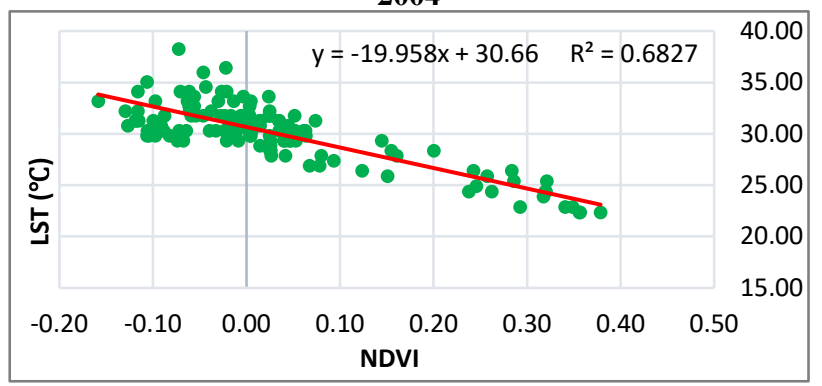

2014

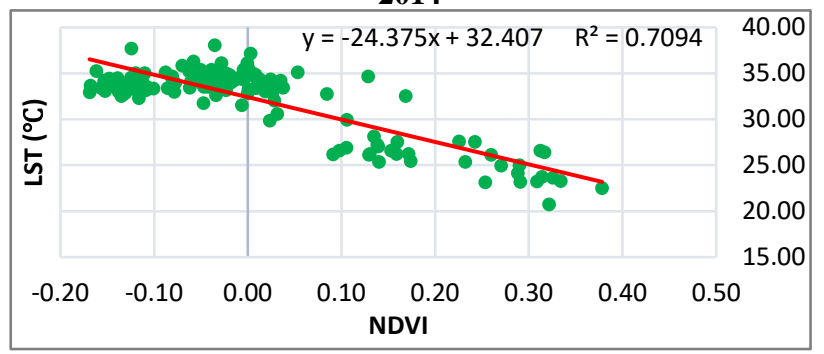

Figure 7. Correlation analysis between LS

As seen in results obtained from the regression analysis in Figure 7 , it was observed that there exists a very strong negative correlation between LST and NDVI with Pearson correlation coefficient values of $\mathrm{R}=-0.826,-0.802,-0.842,-0.859$ for the years 2004, 2008, 2014 and 2018 respectively, all at 95\% confidence interval. The values obtained for the coefficient of determination $\left(\mathrm{R}^{2}\right)$ were all greater than 0.60 . The year 2018 showed the strongest correlation $\left(\mathrm{R}^{2}=0.7380\right)$ between LST and NDVI, while the weaker correlation $\left(\mathrm{R}^{2}=0.6425\right)$ between the two variables was observed in 2008 . The results imply that the vegetation cover has an influence on the mean surface temperature obtainable at a particular location and hence, where vegetation exists, the temperature of that area is less compared to a built environment, affected by anthropogenic activities. Furthermore, it can be deduced from the results of the test of association between LST and NDVI that, the negative relationship of the LST and NDVI values ascertained the cooling impact of forests, woodlands, parks, and other city green spaces.

\section{CONCLUSIONS}

This study gives great insight on the concept of IS and its spatial pattern in Abuja city, Nigeria, over a period of 14 years. It reveals that surfaces such as roads, rooftops, pavements etc. situated in urban areas are highly impervious while surface covered with vegetation possesses lowly impervious. In this paper, the relationship between IS distribution and mean surface temperature of Abuja city, Nigeria have been studied using both qualitative and quantitative analyses. The broad characteristics of IS and their effects in enhancing high surface temperatures have been unveiled. The IS as a variable show a significant bivariate relationship to LST in each period under study. But the Pearson correlation coefficients is smaller in 2008 than in other years. IS proved to be a true indicator of variations in land surface temperature dynamics with a positive linear relationship with LST, whereas LST and NDVI had a negative linear relationship. It was observed that IS contribute to the surface temperature rise

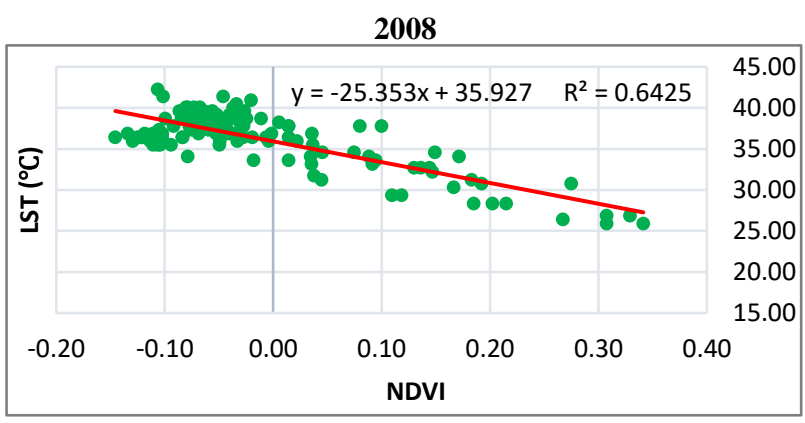

2018

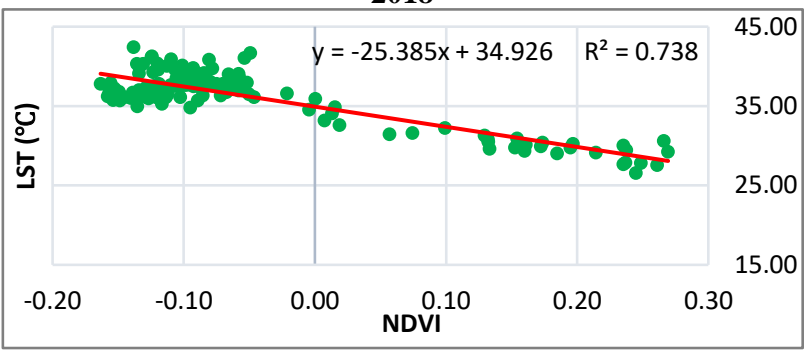

T and NDVI in 2004, 2008, 2014 and 2018.

in Abuja and this can be attributed to anthropogenic activities arising from rapid urbanization which consequently form IS. The study recommends the widespread use of highly reflective or natural surfaces for rooftops, pavements and roads and that afforestation should be encouraged to increase green areas.

\section{REFERENCES}

Adebayo, F.F., Balogun, I.A., Adediji, A.T., Akande, O., Abdulkareem S.B. 2017. Assessment of Urban Heat Island over Ibadan Metropolis Using Landsat and MODIS. International Journal of Environment and Bioenergy, 12(1), 62-87.

Adeyeri, O.E., Okogbue, E.C, Ige, S.O., Ishola, K.A., 2015. Estimating the Land Surface Temperature over Abuja using Different Landsat sensors. In Proceedings of climate change, environmental challenges and sustainable development (pp. 305310). ISBN 978-978-53811-9-1. https://www.researchgate.net/publication/315707126.

Arnold Jr., C.L., Gibbons, C.J., 1996. Impervious surface coverage: the emergence of a key environmental indicator. J. Am. Plann Assoc., 62, 243-258.

Balogun, O., 2001: The Federal Capital Territory of Nigeria: Geography of Its Development. University Press, Ibadan.

Carlson, T.N., Arthur, S.T., 2000. The impact of land use-land cover changes due to urbanization on surface microclimate and hydrology: A satellite perspective. Glob. Planet. Chang., 25, 4965 .

Deng, C., Wu, C., 2012. BCI: A biophysical composition index for remote sensing of urban environments. Remote Sens. Environ., 127, 247-259. 
Hua, L., Zhang, X., Nie, Q., Sun, F., Tang, L., 2020. The impacts of the expansion of urban impervious surfaces on urban heat islands in a coastal city in China. Sustainability, 12(475). doi:10.3390/su12020475.

Humanitarian Data Exchange (HDX) (2020). Nigeria - Subnational population statistics. Retrieved October 14, 2020 from https://data.humdata.org/dataset/nigeria-2016-population-data

Isioye, O.A., Ikwueze, H.U., Akomolafe, E.A., 2020. Urban Heat Island Effects and Thermal Comfort in Abuja Municipal Area Council of Nigeria. FUTY Journal of the Environment, 14(2).

Lia, Z.L., Ning Wanga, H.W., Qiub, S., Sobrino, J.A., Wane, Z., Tanga, B.H., Yanf, G., 2013. Land surface emissivity retrieval from satellite data. International Journal of Remote Sensing, 34(9-10), 3084-3127.

Lillesand, T.M., Kiefer, R.W. 2004. Remote Sensing and Image Interpretation. John Wiley and Sons, Inc., New York, USA.

Liu Z., Wang Y., Peng J. 2010. Remote sensing of impervious surface and its applications: a review. Progress in Geography, 29(9), 1143-1152.

Liu, C., Shao, Z.F., Chen, M., Luo, H., 2013. MNDISI: A multisource composition index for impervious surface area estimation at the individual city scale. Remote Sens. Lett., 4, 803-812.

Meiyappan, P., Jain, A.K., 2012. Three distinct global estimates of historical land-cover change and land-use conversions for over 200 years. Front Earth Sci., 6(2): 122-139.

Meng, Q., Zhang, L., Sun, Z., Meng, F., Wang, L., Sun, Y.X., 2018. Characterizing spatial and temporal trends of surface urban heat island effect in an urban main built-up area: A 12-year case study in Beijing, China. Remote Sens. Environ., 204, 826-837.

Mohapatra, R.P., Wu, C., 2010. High resolution impervious surface estimation. Photogramm. Eng. Remote Sens., 76, 1329 1341.

Okujeni, A., Linden, S.V.D., Hostert, P., 2015. Extending the vegetation-impervious-soil model using simulated EnMAP data and machine learning. Remote Sens. Environ., 158, 69-80.

Qin, N., Jianhua, X., 2014. Understanding the effects of the impervious surfaces pattern on land surface temperature in an urban area. Frontiers in Earth Science, 9(2), 276-285. doi: 10.1007/s11707-014-0459-2.

Sobrino, J.A., Jimenez-Munoz, J.C., Paolini, L., 2004. Land surface temperature retrieval from LANDSAT TM 5. Remote Sensing of Environment, 90, 434-440.

Sterling, S., Ducharne, A., 2008. Comprehensive data set of global land cover change for land surface model applications. Global Biogeochem. Cycles, 22, GB3017. doi:10.1029/2007GB002959.

Sun, G.Y., Chen, X.L., Jia, X.P., Yao, Y.J., Wang, Z.J., 2016. Combinational Build-Up Index (CBI) for effective impervious surface mapping in urban areas. IEEE J. Sel. Top. Appl. Earth Observ. Remote Sens., 9, 2081-2092.

Voorde, T.V.D., Roeck, T.D., Canters, F., 2009. A comparison of two spectral mixture modelling approaches for impervious surface mapping in urban areas. Int. J. Remote Sens., 30, 47854806.

Weng, Q., 2001. A remote sensing-GIS evaluation of urban expansion and its impact on surface temperature in the Zhujiang Delta, China. International Journal of Remote Sensing, 22, 1999-2014.

Wu, H., Ye, L.P., Shi, W.Z., Clarke, K.C., 2014. Assessing the effects of land use spatial structure on urban heat islands using HJ-1B remote sensing imagery in Wuhan, China. Int. J. Appl. Earth Obs. Geoinf., 32, 67-78.

Xian, G., Crane, M., 2006. An analysis of urban thermal characteristics and associated land cover in Tampa bay and Las Vegas using Landsat satellite data. Remote Sens. Environ., 104, $147-156$.

Xu, H., 2010. Analysis of Impervious Surface and its Impact on Urban Heat Environment using the Normalized Difference Impervious Surface Index (NDISI). Photogrammetric Engineering \& Remote Sensing, 76(5), 557-565.

Xu, H., Lin, D., Tang, F., 2013. The impact of impervious surface development on land surface temperature in a subtropical city: Xiamen, China. International Journal of Climatology, 33(2013), 1873-1883. DOI: $10.1002 /$ joc.3554. 